\title{
FMS Inhibitor JNJ-40346527
}

National Cancer Institute

\section{Source}

National Cancer Institute. FMS Inhibitor/N1-40346527. NCI Thesaurus. Code C101519.

A small molecule and orally available inhibitor of colony-stimulating factor-1 receptor (CSF1R; FMS) with potential antineoplastic activity. FMS tyrosine kinase inhibitor JNJ40346527 blocks the receptor-ligand interaction between FMS and its lig and CSF1, thereby preventing autophosphorylation of FMS. As a result, unphosphorylated FMS can not activate FMS-mediated signaling pathways, thus potentially inhibiting cell proliferation in FMS-overexpressed tumor cells. FMS, a tyrosine kinase receptor, is overexpressed in certain tumor cell types and plays an essential role in macrophage differentiation, recruitment, and activation as well as the regulation of cell proliferation. 